\title{
ANALISIS KEBUTUHAN ALAT ANGKUT TBS DI PT. BERAU KARETINDO LESTARI KECAMATAN SEGAH KABUPATEN BERAU PROVINSI KALIMANTAN TIMUR
}

\section{NALYSIS OF THE NEEDS OF TBSDI TRANSPORT EQUIPMENT PT. BERAU KARETINDO LESTARI SUBDISTRICT SEGAH BERAU PROVINSI EAST KALIMANTAN TIMUR}

\author{
Ambrosius Edison ${ }^{1 *}$, Humairo Aziza ${ }^{1}$, Wartomo $^{1}$ \\ ${ }^{1}$ Politeknik Pertanian Negeri Samarinda, Kampus Gunung Panjang, Jl. Samratulangi, \\ Samarinda, Indonesia \\ *corresponding edyson22071996@gmail.com
}

\begin{abstract}
This research is motivated by the processing of palm oil, transportation factors get special attention. The transportation of palm fruit from the garden to the factory should be as fast as possible so that the fruit harvested today can be processed directly so that free fatty acids are not high. Extensive oil palm plantations and garden conditions far from the factory, it will be more difficult to regulate the entry of Fresh Fruit Bunches (TBS) to the Palm Oil Factory (PKS), so that the company must have a good management system that can run effectively and efficiently so that it needs proper transportation for perushan so that it can transport all tbs harvested by minimizing time, cost and maintain the quality of TBS.

From the description above, the formula that can be formulated in this study is to know the time of transportation, the needs of transport equipment and what obstacles are encountered at the time of TBS transportation. While the limitations of the problem there is tbs transport research contained in fadeling Brafo, Alfah and Delta with different distances (near, medium and farthest). The purpose of this research is to know the process of planning the needs of TBS conveyances, as well as knowing the obstacles when transporting TBS.

The results of research conducted at PT. Berau Karetindo Lestari shows that tbs transportation planning includes the production of TBS per day, TBS transport time, availability of conveyance, transportation needs and constraints in transportation. In Bravo afdeling requires 2 units of tarktor, for afdeling Alfah 4 units taktor, and afdeling Delta requires 3 units of tractor. As for the needs of the truck on Loading ramp 1 as many as 10 units and Loading ramp 2 to 8 units. This is obtained after calculating the number of transport equipment needs to transport TBS every day. For the overall needs of the company, tractors are needed as many as 17 and DT as many as 18 units. As for the obstacles at the time of tbs transportation, namely, the road conditions in TPH are not good and the distance of the factory is so far that it takes so much time to get to the factory.
\end{abstract}

Keywords: transportation planning, tarktor needs, truck Dumt needs, and transportation constraints

\section{PENDAHULUAN}

Penelitian ini dilatar belakangi bahwa pengolahan kelapa sawit, faktor transportasi mendapat perhatian khusus. Pengangkutan buah kelapa sawit dari kebun ke pabrik harus secepat mungkin agar buah yang dipanen hari ini dapat diolah langsung sehingga asam lemak bebas tidak tinggi. Perkebunan kelapa sawit yang luas serta kondisi kebun yang jauh dari pabrik, akan lebih sulit untuk mengatur masuknya Tandan Buah Segar (TBS) ke Pabrik Kelapa Sawit (PKS), maka menuntun perusahaan harus memiliki sistem manajemen yang baik yang bisa berjalan dengan efektif dan efisien sehinga perlu transportasi yang tepat bagi perushan sehingga dapat mengangkut seluruh TBS yang dipanen dengan meminimalisir waktu, biaya dan menjaga mutu TBS 
Dalam pengangkutan buah kelapa sawit dari kebun ke Pabrik harus secepat mungkin agar buah yang dipanen hari ini dapat diolah langsung, sehingga asam lemak bebas tidak tinggi. Pengangkutan TBS yang telah dipanen tidak boleh terlalu lama maksimal 8 jam setelah dipanen, bilah lebih dari 8 jam maka Asam Lemak Bebas (ALB) meningka hal ini berdampak pada Mutu Crude Pal Oil (CPO) yang rendah dan rendemen yang kecil. Perkebunan kelapa sawit yang luas yang dimiliki PT. Berau Karetindo Lestari dengan jumlah panen yang berbeda-beda setiap afdeling, serta kondisi kebun yang jauh dari pabrik, sehingga dalam hal ini tidak muda untuk mengatur masuknya Tandan Buah Segar (TBS) ke Pabrik Kelapa Sawit, (PKS) menuntun perusahan tersebut harus memiliki sistem manajemen yang baik membuat perusahan perkebunan kelapa sawit bisa berjalan dengan efektif dan efisien maka perlu penerapan sistem transportasi yang tepat bagi perushan sehingga dapat mengangkut seluruh TBS yang dipanen dengan menimalisir waktu, biaya dan menjaga mutu TBS.

Ketersedian armada yang terbatas merupakan salah satu faktor meneyebabkan restan, salah satu solusi yang ditawarkan untuk mengatasi masalah tersebut adalah dengan memperhitungkan kebutuhan kendaraan pengangkut TBS yang sesuai dengan estimasi panen yang akan dilakukan di kebun kelapa sawit, sehingga semua TBS yang dipanen dapat dikirim ke PKS dan diterima tepat pada waktunya (M.hudori. 2016).

Berdasarkan latar belakang masalah di atas, maka rumusan masalah yang dapat dirumuskan dalam penelitian in yaitu, bagaimana proses perencanaan pengangkutan tandan buah segar, dan faktor kendala apa saja yang ditemukan pada saat pengangkutan TBS dilapangan. Penelitian ini bertujuan untuk mengetahui perencanaan pengangkutan TBS, serta mengetahui kendala pada saat pengangkutan TBS sedang batasan masalah pada penelitian hanya pada pengangkutan TBS yang terdapat pada Afdeling Alfa, Brafo, dan Delta dengan jarak yang jauh, menengah dan terdekat.

\section{METODOLOGI}

Penelitian tugas akhir dilaksanakan di PT. Berau Karetindo Lestari, yang beralamatkan di Kecamatan Segah Kabupanten Berau, provinsi Kalimantan Timur, waktu penelitian dilakukan selam satu bulan di mulai pada tanggal 21 Oktober sampai 21 November 2020.

Alat yang diguanakan dalam penelitian ini berupa; camera handphone, stopwatch, laptop (Microsoft Exel) dan ATK.Sedangkan bahan yang diguanakan; Buah kelapa sawit

Metode pungumpulan data dalam penelitian ini menggunakan dua sumber data berupa data primer dan sekunder untuk mencari dan mengumupulkan data dalam penelitian ini akan di olah yaitu:

Data primer a). Observasi lapangan dilakukan dengan cara mengamati secara langsung pada afdeling dan menentukan afdeling yang akan diteliti. b)Wawancara dilakukan dengan cara pengumpulan data melalu tanya jawab secara langsung kepihak terkait. Data primer yang diperoleh dari wawancara, berupa jumlah kendaraan angkut jenis kendaraan angkut, kapasitas muatan dumpt truk dan traktor dan informasi kebun.d) Dokumentas idilapanga dilakukan dengan cara mendokumentasikan pelaksanaan kegiatan pengangkutan, kondisi lahan yang diteliti dan kondisi jalan pada afdeling yang diteliti dengan tujuan untuk menunjang informasi sudah didapat di lapangan dan membantu dalam menganalisa data.

Data sekunder.Mengumpulkan dokumen/arsip yang mendukung penelitian terdapat pada perusahan khususnya pada estate Long Ayan di tempat penelitian. Data yang diambil 
berupa;data peta kebun, data kondisi jalan, data hasil produksi perhari.

Analisa data yang digunakan adalah data yag diperoleh dari lapangan berupa data primer dan sekunder Menurut Nasir (2014) metode deskripsi adalah suatu dalam meneliti status kelompok manusia, suatu objek, suatu kondis, suatu sistem atau pemikiran, atau kelas peristiwa pada masa sekarang. Tujuan dari penelitian deskripsi ini adalah untuk membuat deskripsi, gambaran atau lukisan secara sistematis, faktual dan akurat mengenai fakta-fakta, sifat-sifat serta hubungan antara fenomena yang terselidik.

Menurut Moleong (2008) penelitian kualitaf merupakan suatu penelitian yang menggunakan latar belakang alamiah serta menafsirkan fenomena yang terjadi dan dilakukan dengan metode yang ada wawancara, pengamatan, dan pemanfaatan dokumen.

Untuk mengetahui kebutuhan alat angkut TBS diperusahan kelapa sawit waktu dalam penganngkutan dilakukan melalui tahap - tahap perhitungan sebagai berikut:

a. Kebutuhan Traktor Afdeling

$$
\frac{\text { Total hasil produksi }(\mathrm{kg})}{\text { kapasitas muat }}
$$

b. Kebutuhan Dumt Truk Afdeling

Total hasil produksi $(\mathrm{kg})$

kapasitas muat

\section{HASIL DAN PEMBAHASAN}

\section{Perencanaan proses pengangkutan}

Hasil pengumpulan data meliputi data hasil produksi TBS, waktu pengangkutan TBS, ketersediaan alat angkut, kebutuhan alat angkut TBS, dan kendala dalam proses pengangkutan.

a. Produksi tandan buah segar (TBS)

Pada tabel 1 dapat diketahui bahwa hasil produksi TBS tertinggi yaitu terdapat pada afdeling Alfa dengan total produksi $87.994 \mathrm{~kg}$ dan merupakan afdeling terluas dengan tahun tanam 2014 sedangkan untuk produksi terendah terdapat pada afdeling Brafo dengan total produksi $52.559 \mathrm{~kg}$ memiliki luas lahan sebesar 362 dengan tahun tanam 2015/2019 dimana setiap masing-masing afdeling memiliki tahun tanam yaang berbeda yaitu pada afdeling Alfah tahun tanam 2014/2015, afdeling Barfo 2015/2019 dan pada afdeling Delata 2015/2016. Hal ini menunjukan bahwa luasan lahan dan tahun tanam yang lama maka akan menghasilkan suatu produksi tinggi sehingga banyak armada pengangkutan yang TBS perlukan Faktor curah hujan sangat berpengaruh terhadap produktivitas kelapa sawit, karena jika curah hujan sedikit maka produktivitas kelapa sawit akan menurun, dan jika hari hujan terlalu banyak maka sinar matahari sebagai proses fotosintesis kelapa sawit akan berkurang sehingga mengakibatkan penurunan hasil panen. Menurut Lubis (2008) unsur kesesuain lahan yanga terpenting adalah, iklim, topogarfi, keadaan fisik dan kimia lahan, erosi, drainase, dan faktor penting lainnya.

Tabel 1. Produksi TBS Perhari Pada Bulan Oktober

\begin{tabular}{ccccc}
\hline Afdeling & $\begin{array}{c}\text { Jumlah } \\
\text { blok }\end{array}$ & $\begin{array}{c}\text { Produksi } \\
\text { TBS } \\
(\mathrm{kg})\end{array}$ & $\begin{array}{c}\text { Tahun } \\
\text { tanam }\end{array}$ & $\begin{array}{c}\text { Luas } \\
\text { lahan } \\
\text { (ha) }\end{array}$ \\
\hline A & 7 & 87.994 & $2014 / 2015$ & 407 \\
B & 8 & 52.559 & $2015 / 2019$ & 362 \\
D & 8 & 55.009 & $2015 / 2016$ & 404 \\
\hline
\end{tabular}

\section{b. Waktu pengangkutanTBS}

Berdasarkan pengamatan lapangan kegitatan pengangkutan dilakukan pada jam 9:00 pagi data yang diambil sebagai sampel ada tiga afdeliing yaitu, Bravo, Alfa dan Delta dengan jarak berbeda yaitu; Afdeling Bravo dengan jarak terdekat, afdeling Alfah dengan Jarak menengah dan Delta dengan jarak jauh sehinga jarak tempu dari TPH ke loding ram berbeda-beda. Dalam kegiatan pengangkutan waktu yang di hitung berupa; garasi ke TPH, waktu muat TBS, TPH ke Loding Ram, Loding Ram ke TPH, isi minyak, istirahat, dapat di lihat pada lampiran 8. Pada tabel.3 Dibawa ini merupakan hasil pengamatan waktu 
Edison, A., Aziza, H. dan Wartomo .(2021) "Analisis Kebutuhan Alat Angkut Tbs Di PT. Berau Karetindo Lestari Kecamatan Segah Kabupaten Berau Provinsi Kalimantan Timur", Jurnal Agriment, 6(2).

pengangkutan TBS dari TPH ke Loding

Ram.

Tabel 2. Hasil Perhitungan Waktu Muat Tbs Pada Traktor

\begin{tabular}{lcccc}
\hline Afdeling & $\begin{array}{c}\text { Jarak TPH- LR } \\
(\mathrm{KM})\end{array}$ & Waktu siklus $(\mathrm{m})$ & $\begin{array}{c}\text { Kapasitas } \\
\text { muat }(\mathrm{Kg})\end{array}$ & $\begin{array}{c}\text { Produktivitas } \\
(\mathrm{Kg} / \mathrm{jam})\end{array}$ \\
\hline Bravo & 2,70 & 94 & 4.027 & 2.369 \\
Alfah & 3,62 & 102 & 3.924 & 2.308 \\
Delta & 3,72 & 125 & 3.681 & 1.843 \\
\hline
\end{tabular}

Tabel 3. Hasil Perhitungan Waktu Muat Pada Dump Truck

\begin{tabular}{cccccc}
\hline $\begin{array}{c}\text { Jenis Alat } \\
\text { Angkut(DT) }\end{array}$ & $\begin{array}{c}\text { Loding } \\
\text { Ram }\end{array}$ & $\begin{array}{c}\text { Jarak Loding } \\
\text { Ram ke PKS } \\
(\text { KM) }\end{array}$ & $\begin{array}{c}\text { Waktu } \\
\text { Siklus }\end{array}$ & $\begin{array}{c}\text { Kapasitas } \\
\text { Muat }\end{array}$ & $\begin{array}{c}\text { Produktivitas Alat Angkut } \\
\text { (kg/jam) }\end{array}$ \\
\hline V. 05 & 01 & 84 & 178 & 6.855 & 2.315 \\
V. 09 & 02 & 89 & 237 & 6.798 & 1.721 \\
\hline
\end{tabular}

Tabel 4. Ketersedian Alat Angkut TBS

\begin{tabular}{cccccc}
\hline Afdeling & $\begin{array}{c}\text { Jenis Alat } \\
\text { Angkut TBS }\end{array}$ & $\begin{array}{c}\text { Ketersedian Alat } \\
\text { Angkut }\end{array}$ & $\begin{array}{c}\text { Loading } \\
\text { Ram }\end{array}$ & Jenis Alat Angkut & $\begin{array}{c}\text { Ketersedian } \\
\text { Alat Angkut }\end{array}$ \\
\hline Brafo & traktor & 1 & 1 & Dumpt truck & 7 \\
Alfa & traktor & 1 & 2 & Dumpt truck & 2 \\
Delata & traktor & 1 & & & \\
\hline
\end{tabular}

Sumber data PT. BKL

Dari tabel 2, hasil perhitungan waktu pengangkutan TBS untuk jarak afdeling terdekat yakni Brafo di peroleh waktu muat 94 menit dalam 1 trip, dengan kapsitas muat rata-rata $4.027 \mathrm{~kg}$ berjarak dari TPH ke Loding ram sejauh 2,7 km. Sedangkan jarak untuk jarak menenengah yaitu Pada afdeling Alfah diperoleh waktu muat selama 102 menit dengan kapasitas muat rata-rata sebanyak $3.924 \mathrm{~kg}$ dengan jarak perjalanan sejauh $3,62 \mathrm{~km}$, pada afdeling Delta dengan yang jauh diperoleh waktu muat selama 125 menit dengan kapasitas muat sebanyak $3.681 \mathrm{~kg}$ berjarak sejauh $3,72 \mathrm{~km}$. Hal ini menunjukan bahwa semakin dekat jarak afdeling dengan loading ramp maka semakin besar kapasitas muatnya begitupun sebalik jika afdeling afdeling dengan jarak jauh maka kapasitas muatnya semakin sedikit. Dari hal tersebut maka diperoleh setiap masing-masing afdeling memiliki produktivitas alat angkut yang berbeda. Pada afdeling Brafo diperoleh sebanyak $2.369 \mathrm{~kg} / \mathrm{jam}$, untuk afdeling Alfah diperoleh sebanyak 2.308 $\mathrm{kg} / \mathrm{jam}$ sedangkan pada afdeling delta diperoleh 1,843. Menurut pendapat Fauzi (2012) tandan buah segar harus segera di angkut ke pabrik dengan waktu maksimal 8 setelah dipanen jika buah yang telah di panen tidak diolah akan mengalami kerusakan dan terjadinya meningkatnya Asam Lemak Bebas (ALB).

Dari tabel 3, hasil perhitungan waktu muat TBS untuk DT V.05 memperoleh waktu pengangkutan 178 menit dari Loding Ram 01 ke pabrik kelpa sawit dengan jarak sejauh 84 yang berkapsitas muat TBS $6.855 \mathrm{~kg}$ dalam satu trip. untuk DT V.09 diperoleh waktu muat TBS selama 237 menit dengan kapsitas muat sebanyak $6.798 \mathrm{~kg}$ dalam satu trip dengan jarak Loading Ram 02 ke PKS sejauh $89 \mathrm{~km}$, dengan memiliki produktivitas yang berbeda pada DT 05 
diperoleh $2.315 \mathrm{~kg} / \mathrm{jam}$ sedangkan pada DT V.09 diperoleh $1.721 \mathrm{~kg} / \mathrm{jam}$. Hal ini menujukan bahwa jarak yang semakin jahu lebih sedikit mengakut TBS sebaliknya jika jarak yang lebih dekat maka TBS yang di angkut lebih banyak.

c. Ketersediaan alat angkut TBS bulan Oktober 2020

Hasil pengamatan lapangan jenis alat angkut yang diterapkan perusahan yaitu berupa traktor dan dumpt truck untuk mengangkut hasil produksi TBS, dimana traktor digunakan untuk mengangkut TBS dari TPH ke loading sedang digunakan untuk mengangkut TBS dari Loading ramp ke pabrik. Berikut ketersediaan alat angkut dapat dilihat pada tabel di bawah

Dari tabel 4 dapat dijelaskan bahwa ketersedian alat angkut TBS di perusahan menggunakan dua jenis alat angkut yaitu traktor dan Dump truk dengan tipe kendaraan massey ferguson dan dyna 130 Ht. Dimana dari masing-masing afdeling hanya disediakn 1 traktor sedang untuk Loading ram 01 disedikan sebanyak 7 unit DT dan loading rampt 02 sebanyak 2 unit DT.

\section{d. Kebutuhan alat angkut}

Dari observasi dilapangan bahwa Traktor digunakn sebagai alat pengangkutan TBS dari TPH ke Loading ramp dengan kapasitas muat sebanyak 34 ton per reits. untuk mengetahui kebutuhan alat digunakan rumus sebagai berikut;

KebutuhanTraktor $=\frac{\text { Total Hasil Produksi }(\mathrm{kg})}{\text { kapasitas Traktor }}$

Sehingga diperoleh kebutuhan Traktor pada masing afdeling dapat dilihat pada tabel 5.

Tabel 5. hasil perhitingan kebutuhan traktor

\begin{tabular}{cccccc}
\hline Afdeling & $\begin{array}{c}\text { Jarak TPH }- \text { LR } \\
(\mathrm{Km})\end{array}$ & $\begin{array}{c}\text { Total waktu } \\
\text { siklus (menit) }\end{array}$ & $\begin{array}{c}\text { Total } \\
\text { Produksi }\end{array}$ & $\begin{array}{c}\text { Rata-rata } \\
\text { Kapasitas } \\
\text { Muat }\end{array}$ & $\begin{array}{c}\text { Kebutuhan } \\
\text { Traktor }\end{array}$ \\
\hline Brafo & 2,7 & 94 & 52.559 & 3.924 & 2 \\
Alfah & 3,62 & 102 & 87.994 & 4.027 & 4 \\
Delta & 3,72 & 125 & 55.009 & 3.839 & 3 \\
\hline
\end{tabular}

Tabel 6. Hasil perhitungan Kebutuhan Dump Truck

\begin{tabular}{ccccccc}
$\begin{array}{c}\text { Loding } \\
\text { Ram }\end{array}$ & Afdeling & $\begin{array}{c}\text { Jarak } \\
\text { LR-PKS }\end{array}$ & $\begin{array}{c}\text { Total Waktu } \\
\text { Siklus (menit) }\end{array}$ & $\begin{array}{c}\text { Total Produksi } \\
\text { Perhari (kg) }\end{array}$ & $\begin{array}{c}\text { Kapasitas } \\
\text { Muat (kg) }\end{array}$ & $\begin{array}{c}\text { Kebutuhan } \\
\text { DT }\end{array}$ \\
\hline 01 & $\begin{array}{c}\text { Alfah } \\
\text { Brafo } \\
\text { Charly } \\
\text { Delta } \\
\text { Eko }\end{array}$ & 84 & 178 & 198.600 & 6.855 & 10 \\
02 & 89 & 237 & 110.429 & 6.798 & 8 \\
\hline
\end{tabular}

Dari tabel 5 dapat dilihat produksi terendah pada afdeling Brafo sebanyak $52.559 \mathrm{~kg} / \mathrm{hari}$, dengan waktu pengangkutan selama 94 menit. Sehinga dibutuhkan 2 unit saja untuk mengangkut hasil produks TBS perhari. Pada afdeling Alfah total produksi sebanyak 87.994 $\mathrm{kg} /$ hari, merupakan produksi TBS tertinggi dengan rata-rata kapsitas muat sebanyak $4.027 \mathrm{~kg} /$ trip, dengan membutuhkan waktu proses pengangkutan selama 125 menit. setelah melakukan perhitungan kebutuhan aramda transportasi, afdeling Alfah hanya membutuhkan 4 unit traktor untuk mengangkut hasil produksi perharinya dari TPH ke Loading Ram. Afdeling Delta dengan hasil produksi sebanyak 55.009 $\mathrm{kg} /$ hari berkapasitas muat sebanyak 3.839 $\mathrm{kg} / \mathrm{hari}$ dibutuhkan trakor sebanyak 3 unit untuk mengangkut hasil produksi TBS perharinya. Sedangkan untuk perhitungan kebutuhan DT menggunakan rumus sama 
seperti kebutuhan traktor berikut adalah rumus kebtuhan DT.

Kebutuhan DT $=\frac{\text { Total Hasil Produksi }(\mathrm{kg})}{\text { kapasitas Traktor }}$

Setelah melakukan perhitungan maka kebutuhan DT di setiap loding ram dapat dilihat pada tabel 6. Dari tabel tersebut dapat dilihat bahwa loding Ram 01 dapat menampung produksi sebanyak $198.600 \mathrm{~kg} / \mathrm{hari}$, dengan rata-rata kapasitas muat Dump Truck sebanyak $6.855 \mathrm{~kg} /$ trip, dengan membutuhkan waktu proses pengangkutan selama 178 menit. setelah melakukan Perhitungan kebutuhan Alat angkut, dibutuhkan DT sebanyak 10 unit untuk mengangkut hasil produksi dari tiga Afdeling perharinya dari Loading Ramp ke PKS. Pada loading Ramp 02 dapat menampung produksi sebanyak $110.429 \mathrm{~kg} / \mathrm{hari}$, dengan waktu pengangkutan selama 237 menit sehingga di butuhkan DT sebanyak 8 unit untuk mengangkut TBS dari Loding Ram ke PKS. Hal ini menunjukan bahwa hasil produksi TBS semakin tinggi maka jumlah Tabel: 7. Hasil Perhitungan Kebutuhan Traktor PT. BKI Di Estate Long Ayan

\begin{tabular}{cccc}
\hline Afdeling & Produksi TBS $(\mathrm{kg} / \mathrm{hri})$ & $\begin{array}{c}\text { Produktivitas traktor } \\
(\mathrm{kg} / \mathrm{jam})\end{array}$ & Kebutuhan Alat angkut \\
\hline Brovo & 52.559 & 20.928 & 2 \\
Charly & 58.053 & & 4 \\
Alfah & 87.994 & 18.994 & 3 \\
Eko & 55.420 & & \\
Delta & 55.009 & 14.760 & 17 \\
\hline Jumlah & 309.029 & 54.682 & \\
\hline Rata -rata & & 18.273 &
\end{tabular}

Tabel;8 Perhitungan Kebutuhan Dump Truck PT BKL di estate loang ayan

\begin{tabular}{|c|c|c|c|c|}
\hline Afdeling & $\begin{array}{l}\text { Produksi TBS } \\
\text { (kg/hari) }\end{array}$ & Loding Ram & $\begin{array}{c}\text { Produktivitas } \\
\text { Dump Truck }(\mathrm{kg} / \mathrm{jam})\end{array}$ & $\begin{array}{c}\text { Kebutuhan } \\
\text { Dumtruk }\end{array}$ \\
\hline Brafoh & 52.559 & & & \multirow{3}{*}{10} \\
\hline Alfah & 87.994 & 01 & 12.469 & \\
\hline Charly & 58.053 & & & \\
\hline Delta & 55.009 & 02 & 122 & \multirow[t]{2}{*}{8} \\
\hline Eko & 55.420 & 02 & $12.2 / 2$ & \\
\hline Jumlah & 309.029 & & 24.741 & \multirow[t]{2}{*}{18} \\
\hline Rata-rata & & & 12.370 & \\
\hline
\end{tabular}

2. Kebutuhan Dumpt truk

Dari tabel 8 dapat dilihat kebutuhan

Dumtruk pada PT. Berau Karetindo Lestrai unit semakin banyak dibutuhkan berdasarkan hasil produksi TBS/hari.

e. Kebutuhan traktor dan Dumpt truck pada PT BKL

Berdasarkan data produktivitas traktor dan DT pada pengangkutan di Afdeling Brafo, Alfa, dan Delta serta produktivitas pada PT. BKL maka kebutuhan Traktor Dan DT Pengangkutan TBS yang secara lengkap dapat dilihat pada tabel 7 dan tabel 8 dibawah ini.

\section{Traktor}

Berdasarkan tabel 7 kebutuhan traktor pada PT. Berau Karetindo Lestari khususnya estate Long ayan sebanyak 17 unit terdistribusi pada Afdeling Brafo sebanyak 2 unit, Alfah 4 unit dan Delta sebanyak 2 unit. Untuk kebutuhan Traktor secara teliti pada afdeling Charly dan Ekho perlu dilakukan perhitungan tersendiri dengan dasar data produktivitas traktor pada afdeling tersebut. Untuk kebutuhan Dump Truck dapat dilhat pada tabel 8. 
hasil produksi TBS, terdi dari Afdeling Brafo,Alfah, Charly sehingga dibutukan dumtruk sebanyak 15 unit sedangkan pada Loding Ram 02 yang menampung hasil produksi TBS terdiri dari afdeling Delta dan Eko, dibutuhkan dumtruk sebanyak 8 unit untuk mengankut Produksi TBS perharinya. Hasil penelitian ini desesuikan dengan penelitian terdahulu yang dilakukan oleh Tirta Yoga, (2017) dengan judul Efektivitas Sistem Pengangkutan Bahan Baku Tandan Buah Segar (TBS) Kelapa sawit dimana hasil penelitian memperlihatkan bahwa kebutuhan unit transportasi untuk masingmasing afdeling bervariasi tergantung dari siklus angkutan dan jumlah produksi harian yang dihasilkan kebun.

\section{Hambatan pada saat pengangkutan}

Kondisi jalan perlu diperhatikan karena jalan merupakan salah satu faktor utama dalam keberhasilan pengangkutan yang dilalui kendara angkut.dari hasil pengamatan lapangan kondisi jalan afdeling maupun blok yang rusak dapat dilihat tabel berikut;

Tabel.9 Kondisi Jalan Rusak PT BKL 2020

\begin{tabular}{cccc}
\hline Afdeling & $\begin{array}{c}\text { Panjang } \\
\text { jalan } \\
\text { rusak }\end{array}$ & $\begin{array}{c}\text { Collection } \\
\text { road } \\
\text { rusak }\end{array}$ & $\begin{array}{c}\text { Main } \\
\text { road } \\
\text { rusak }\end{array}$ \\
\hline Alfah & $1.050 \mathrm{~m}$ & 9 & 5 \\
Brafo & $500 \mathrm{~m}$ & 11 & 3 \\
\hline Delta & $2.150 \mathrm{~m}$ & 17 & 12 \\
\hline
\end{tabular}

Dari tabel 9 diketahui kondisi jalan afdeling dan blok rusak terbanyak terdapat pada afdeling Delta dengan total jumlah jalan rusak sebanyak $2.150 \mathrm{~m}$ yang terdiri dari jalan CR yang rusak 17 titik dan jalan MR 12. Sedangkan kondisi jalan afdeling dan blok paling sedikit yaitu afdeling Brafo dengan total jumlah jalan rusak $500 \mathrm{~m}$ yang terdiri dari jalan CR 11 titik, dan jalan MR,3 titik. Kondisi jalan MR maupun CR di afdeling salah satu faktor dipengaruhi curah hujan tinggi, pada lokasi penelitian memiliki iklim tropis basa sehinga menyebabkan musim kering dan musim basa masi diatas $100 \mathrm{~mm}$ perbulannya. Jika curah hujan yang tinggi akan mempersulit untuk pengangkut TBS sehingga banyak buah restan yang terjadi. Dibawa ini merupakan Tabel curah hujan pada tahun 2020 .

Tabel.10 Curah hujan dan hari hujan pada tahun 2020

\begin{tabular}{ccc}
\hline Bulan & $\begin{array}{c}\text { rata-rata } \\
\text { hari hujan } \\
(\mathrm{HH})\end{array}$ & $\begin{array}{c}\text { rata rata } \\
\text { curah hujan } \\
(\mathrm{C}) \mathrm{H}\end{array}$ \\
\hline Januari & 30 & 488,9 \\
Februari & 16 & 110 \\
Maret & 11 & 124,7 \\
April & 11 & 152,2 \\
Mei & 17 & 654,49 \\
Juni & 10 & 182 \\
July & 4 & 129 \\
Agustus & 8 & 137 \\
September & 5 & 129 \\
Oktober & 5 & 25,8 \\
November & 8 & 338 \\
Desember & 9 & 346,5 \\
\hline
\end{tabular}

Dari tabel 10 dapat dihasilkan kesimpulan bahawa rata - rata hari hujan yang tinggi yaitu pada bulan januari sebanyak 30 hari dengan rata - rata curah hujan yaitu 488,9. Lamanya hujan dalam jam kerja panen,hal ini akan berdampak pada kondisi permukaan jalan,yang dilalui seperti jalan utama, jalan penghubung dan jalan produksi serta kegitaan panen maupun kegiatan pengangkutan tandan buah segar.

\section{KESIMPULAN}

Dari hasil penelitian ini dapat disimpulkan beberapa hal sebagai berikut:

1. Pada PT.Berau Karetindo Lestari Proses perencanaan pengangkutan meliputi perhitungan hasil produksi, waktu pengangkutan, ketersediaan alat angkut TBS dan kebutuhan alat angkut TBS. Hasil produksi TBS tertinggi terdapat pada afdeling Alfa dengan kebutuhan alat angkut sebanyak 4 unit traktor sedangkan untuk hasil produksi terendah terdapat pada afdeling Brafo dibutuhkan 2 unit traktor. Untuk jumlah unit pada PT. Berau Karetindo Lestari khususnya estate long ayan dibutuhkan sebanyak 17 unit traktor dan DT sebanyak 18 unit. Pada 
proses pengangkutan TBS dari afdeling memerlukan waktu yang berbeda baik dari TPH ke Loading rampt maupun hingga sampai di pabrik.

2. Faktor yang menjadi kendala dalam pengangkutan Tandan Buah Segar adalah kondisi lapangan seperti topografi lahan, dan kondisi jalan yang akan memperlambat dalam proses pengangkutan buah sehingga banyak memakan waktu yang cukup lama. Pada musim hujan yang menjadi kendala dalam kegiatan panen, maupun pengangkutan TBS ialah kondisi jalan menjadi menjadi licin, dan rusak karena kurangnya cahaya matahari. Kerusaknya jalan disebabkan beban muatan yang berlebihan dan alat berat yang melawati jalan sehingga mengakibatkan jembatan maupun jalan menjadi rusak yang akan menghambat dalam proses pengiriman TBS dari lapangan ke pabrik.

\section{DAFTAR PUSTAKA}

Krisdiarto,L. S. (2017). Optimasi Kualitas Tandan Buah Segar Kelapa Sawit dalam Proses Panen-Angkut. AGRITECH, 101-107.

Lumbantoruan,D. dkk. (2013). Penentuan Jumlah Produksi Optimal CPO dengan Menggunkan. Metode goal programming pada pabrik kelapa sawit PT. XYZ e-Jurnal Teknik Industri FT USU, 45-51.

Hariyadi, D.(2019). Manajemen Panen Kelapa Sawit (Elaeis gueneensis Jacq.) di Seruyan Estate, Kebun Minamas,. Bul. Agrohorti, 311-318.

Lubis, M. F. (2008). Analisis Produksi Kelapa Sawit (Elaeis Guineensis Jacq.) Di Kebun Buatan, Kabupaten Pelalawan,. Bul. Agrohorti , 281 - 286 .Sugiyono. 2017 Metode Penelitian Kuantitatif Kualitatif, R\&D. Bandung :Alfabeta,

M.Hudori. (2016). Perencanaan kebutuhan kendaraan angkutan
Tandan Buah Segar (TBS) perkebunan kelapa sawit. Malikussaleh Industrial Engineering Journal Vol.5 No.1 (2016) 22-27 , 27.

Sari, M. (2015). Efektifitas Pengangkuttan Tandan Buah Segar Kelapa Sawit. skripsii, Medan: Sekolah Tinggi IImu Pertania.

Supriadi, S. (2015). Analisis Produksi dan Produktifitas Perkebunankelapa sawit Rakyat di Kabupa. Skripsi, Medan.

Sunarko. 2014. Budidaya Kelapa Sawit Di Berbagai Jenis Lahan. Jakarta: Agro Media Pustaka.

Yoga, T. (2006). Efektivitas Sistem Pengangkutan Tandan Buah Segar (TBS) Kelpa sawit (Elaeis Gunneensis) Dalam Meningkatkan Mutu Dikebun. Universitas Brawijaya, 80.

Fauzi (2012). budidaya kelapa sawit. penebar Swadaya.jakarta

Pahan, I (2006). Panduan Lengkap kelapa sawit Manajemen Agribisinis dari Hulu hingga Hilir. Penerbit Penebar Awadaya, Jakarta

Mangoensoekarjo $\mathrm{S}$ dan semangun $\mathrm{H}$. (2008). Manajemen Agrobisnis kelapa sawit. Gadjah Mada University Press Yogayakarta. Hal 605.

Setyamidjaja, D.(1991). Seri Budidaya Kelapa Sawit, Teknik Budidaya, Panen, Pengelolahan. Yogyakarta 